\title{
Perception towards online/blended learning at the time of Covid-19 pandemic: an academic analytics in the Indian context
}

Ritimoni Bordoloi

Discipline of Education, Krishna Kanta Handiqui State Open University, Guwahati, India

Prasenjit Das

Discipline of English, Krishna Kanta Handiqui State Open University, Guwahati, India, and

Kandarpa Das

Vice Chancellor, Krishna Kanta Handiqui State Open University, Guwahati, India

\begin{abstract}
Purpose - During any crisis situation like a pandemic, war or natural disaster, online/blended learning could meet the academic needs of the learners in a bigger way. The use of information and communication technology (ICT)-based technologies has converted the entire teaching pedagogy to a learner centred pedagogy, following which the skills of using technology are to be seen as the most essential qualifications on the part of both the teachers/educators and learners. Therefore, the purpose of this paper is to understand the perceptions of the teachers and learners regarding the use of online/blended learning modes in teaching learning transactions. Another purpose of the paper being to find out the prospects and challenges of providing online/blended learning in a country like India, particularly during and in post-Covid-19 situations.

Design/methodology/approach - The academic analytics approach was used for the study. A structured questionnaire was designed in Google Forms covering the perceptions of the teachers and learners in different Indian universities and colleges regarding online/blended services and analysis was done using Google Analytics. Further, analysis of the data received had been done by using simple statistical tool like percentage. Findings - Blended learning could be the solution for providing education in the context of the 21st century India. However, unlike in case of the conventional education, open education has widened the scope of learning adhering to the motto - "Bring your own device" to learn. The extensive use of open educational resources, massive open online courses, social media and meeting apps during the Covid-19 lockdown, has opened up the minds of the knowledge-hungry people, further enabling them to receive the necessary educational inputs, training and skills even during the current pandemic situation. This is going to have a big impact in the ways of educational transactions in the days to come.

Research limitations/implications - The discussions in the paper are limited to a study of representative states of India, and it is a general study only. The sample size was limited to only 120 as the response rate was significantly low compared to the number of addressees to whom the questionnaire was sent.

Practical implications - This study will help in understanding the present state of online/blended learning in a country like India. The use of online learning was no doubt intensified by the sudden outbreak of the Covid-19 Pandemic. However, the study will also help in preparing a roadmap, at the policy level, regarding the beneficial use of online/blended teaching learning models both by the teachers and learners during any future crisis-like situations in a country like India.
\end{abstract}

(C) Ritimoni Bordoloi, Prasenjit Das and Kandarpa Das. Published in the Asian Association of Open Universities Journal. Published by Emerald Publishing Limited. This article is published under the Creative Commons Attribution (CC BY 4.0) licence. Anyone may reproduce, distribute, translate and create derivative works of this article (for both commercial and non-commercial purposes), subject to full attribution to the original publication and authors. The full terms of this licence may be seen at http:// creativecommons.org/licences/by/4.0/legalcode
Received 24 October 2020 Revised 30 December 2020 29 January 2021

Accepted 1 February 2021 
AAOUJ 16,1

Social implications - Through this paper, a new social constructivism has been visualised to know the acceptability of online/blended learning opportunities on the part of the teachers and learners across India. If that social constructivism can actually be realised through the benefits of online learning, India might emerge as one of the important leaders of education in the coming days. To that extent, the Covid-19 pandemic can be seen as a blessing in disguise.

Originality/value - It is important to examine the perceptions of both teachers and learners on the use of online learning in their regular curriculum transactions most particularly when the whole world is facing the brunt of the Covid-19 pandemic, which has adversely affected millions of learners across the world. The paper is original because it explores the current state of online/blended learning in a developing country like India to provide a practical and realistic vision of a new way of learning in the post-Covid-19 situations.

Keywords Techno-pedagogy, Online/blended learning, Academic analytics, Covid-19 pandemic, Sustainable education, Perceptions of teachers and learners

Paper type Research paper

\section{Introduction}

The 21st century education calls for personalised, productive and collaborative teachinglearning experiences that are expected to transform the entire education system from traditional face-to-face $(\mathrm{F} 2 \mathrm{~F})$ mode to techno-based independent mode where the basic focus will be laid on developing the potentials and creativity of the learners in the best possible ways. However, providing equal access to education, guaranteeing equity and justice, ensuring timely delivery of need-based educational contents, engaging the learners through a carefully planned pedagogical support with the latest online/blended learning technologies could be seen as the catalyst for change as well as the solution for establishing the democratic principle of education as a whole. Along with conventional education, open education has widened the scope of learning opportunities through the emerging theme of "Bring your own device" to learn. Besides, open educational resources (OERs) and massive open online courses (MOOCs), some other digital learning platforms such as online meetings apps like Zoom, Google Meet, Cisco WebEx, etc. have provided myriad learning opportunities to the learners by opening up their minds and helping them to gain need-based training and skills which are the most essential prerequisites for a healthy living in a society.

So, with the boom in online technologies and an increasing use of internet and social media for imparting education in the 21st century, a new social constructivism has been in place so that teachers can reach out to each learner or learners can directly interact with their teachers and share their ideas and thoughts with their peers. Several studies have been conducted on how online learning has transformed the field of education in the 21st century and in what ways they are so rewarding experiences. For example, Mckay et al. (2018) referred to changing educational landscape in California Community colleges. Since the conduct of fully online courses nearly 20 years ago, the traditional distance education gradually evolved into a system that engaged both teachers and learners in an interactive online environment, a system in which content is delivered through varied means. They mentioned how the subsequent developments in online technology had led to the creation of courses that could rival and even surpass the in-person classroom experiences in terms of the flexibility in learning and assessment. They also opined that the use of OERs is yet another way to aid the learners who might not be able to afford physical textbooks, as most OER materials are available digitally. In another context, Harrad and Banks (2016) referred to the use of online learning in providing psychological therapy in the UK. They highlighted the importance of the theory and research of online counselling methods to further explore the possible effectiveness of online therapies and the factors that impact this effectiveness so that clients gain the best clinical outcomes. Their view is that the nature of online counselling enhances and expands opportunities to connect people, rather than being just an alternative or substitute for F2F interaction. Similarly, Hass and Joseph (2018) examined students' perceptions on online vs traditional $(\mathrm{F} 2 \mathrm{~F})$ courses offered at the business schools of a liberal 
arts university in Southwest USA The research compared perceptions of the students who

had been subjected to online education along with those who had not been exposed to such education and examined the likelihood of the students willing to take online courses. The authors proposed a hybrid model incorporating the resources from both.

Following the outbreak of the Covid-19 pandemic, there began a renewed interest on the role and utility of online and digital learning at the time of a crisis across the whole world. The different experiments with collaborative learning, constructive learning, cooperative learning and transformative learning (TL) have shown that by adopting accessible, flexible and affordable technologies in education and by integrating in person and online activities while framing the learning objectives and assessing the expected learning outcomes of the learners, newer and effective ways of learning experiences can be visualized. And, when our society faces a crisis like a pandemic, war or any kind of natural disaster, such ideas of education might significantly help. For example, Baytiyeh (2018) discussed the impact of seismic events like earthquakes on educational services, while asserting the crucial role played by ICTs in delivering education even during temporary closure of educational institutions following a natural disaster like earthquake. Some studies have specifically dealt with the perceptions of the faculty and students on the use of online learning at the time of the pandemic. Davis et al. (2020), for example, mentioned about the utility of using TL as a framework at the individual level by five faculty members teaching English courses at Duke Kunshan University (DKU), based in China. The authors opined that through TL, they were able to get rid of the negative effects, minimise anxiety and alleviate much of the academic and mental pressure caused by the pandemic. Peake and Reynolds (2020) also conducted a study among the staff and students of the University of Bordeaux during the pandemic. The authors mentioned that the virtual language centre of the university was established to ensure that students benefit from social media that would direct them to useful resources and to create an online virtual community to keep communication open among all those who had been involved.

While referring to the Covid-19 pandemic as the greatest challenge the education systems across the world have currently faced, Sir Daniel (2020) mentioned how several governments have ordered institutions to switch, almost overnight, from F2F to online teaching and virtual education for the learners. Sir John also offered some pragmatic guidance to the teachers, institutional heads and state officials who should be able to address the educational concerns of the present crisis and thereby frame timely guidelines to cover issues like providing education that would meet students' needs at different stages of their academic lives, make room for flexible approaches to remote learning, renewed focus on curricula development, assessment, etc. Assuming the possibility of future recurrence of Covid-19, he urged all educational institutions, educators/teachers and students to continuously explore flexible ways to repair the damage already caused by the coronavirus. In this context, the National Institute of Open Schooling of India, the New Zealand Correspondence School and open universities like the UK Open University; Athabasca University, Canada, among others, which continued to function even during the present pandemic can show the world the much needed way to get back on track.

The Indian higher education system is the third largest system after China and the USA. At present, as per the record available in All India Survey of Higher Education (AISHE), 2019, there are 993 universities, 39,931 colleges and 10,725 standalone institutions across India. Out of the total number of universities, only 14 are state open universities, one central open university. The top eight states in terms of the highest number of colleges in India are - Uttar Pradesh, Maharashtra, Karnataka, Rajasthan, Andhra Pradesh, Tamil Nadu, Gujarat and Madhya Pradesh. Yet, the number of such institutions is comparatively less against the total population of this vast country, and access to higher education by every Indian citizen is still a dream. Regarding the total enrolment in higher education, only $54 \%$ are male and $46 \%$ female. The gross enrolment 
AAOUJ

16,1 ratio (GER) is still not reaching 30\% (now 25.8\%). By using the 21st century digital skills, the Government of India (GOI) has tried to carry forward the knowledge movement among the people of the nation. However, the stated goals of the Indian higher education such as dissemination of knowledge, use of information networks and mass media technologies, improving productivity, etc. - are to be seen as the only ways of ensuring employability on the part of the Indian learners.

So, along with the F2F, open and distance learning (ODL) has apparently played an important role by contributing to the formation of the knowledge population in India. As ODL is widely accepted as a means of providing flexible access to higher education, since 1980, the GOI has been giving due emphasis on the expansion of higher education through the ODL mode, which accounts for about $11 \%$ of the total enrolment in the segment of higher education as per the AISHE Report 2019. (Bordoloi, 2018) But, to ensure a sustainable education system and to meet the mission and vision of the government initiations like "Startup India" and "Skilled India", the learners should be able to reap the benefits of the techno-based education in an equitable way. In view of the potential of MOOCs in transforming the educational landscape of the present-day society, the Ministry of Human Resource Development, the GOI introduced "Study Webs of ActiveLearning for Young Aspiring Minds" (SWAYAM) in 2016. Subsequently, the University Grants Commission (UGC) through the Credit Framework for Online Learning Courses through SWAYAM Regulation, 2016, mentioned that at least $20 \%$ materials, and in 2020 , it was decided that at least $40 \%$ from the total number of courses by an Indian university should be released in the form of MOOCs for the fast dissemination of knowledge and information among the prospective Indian learners. But, one of the major problems related to the SWAYAM is the high rate of dropout (UGC Regulations, 2020). There may be some other factors too such as - the syllabi not being at par, course contents failing to motivate the learners, difficulty in credit transfer and so on. But, another important issue is also that both the teachers and learners are notable to properly handle such types of online courses as they are not accustomed or trained to use a digital device as well as the technology for the purpose of learning.

Hasan (2020), who conducted a qualitative survey on 408 students to know their perspectives on online teaching-learning during the pandemic-induced lockdown, mentioned that online teaching emerged as a potential tool to support students' learning remotely. To ensure that education at all levels could continue, the educational institutions across India and worldwide switched to online mode of teaching-learning. The practical usage of platforms such as WebEx, Zoom, Google Meet, Say Namaste, as well as learning management systems (LMS) like Moodle, Blackboard, etc. had been encouraged to support students' learning in all possible ways during the lockdown. However, this abrupt and unexpected shift to online mode of teaching in India where a rampant digital divide still exists and where a large number of learners still belong to the disadvantaged groups, internet accessibility and unaffordable technology were more likely to make learning beyond the reach of thousands of learners. The biggest challenge, however, was to make learning accessible and worthy to the learners of all ages and stages in this moment of crisis. The author opined that instead of starting online teaching in an unplanned and hurried way, understanding students' priorities and challenges while learning online would help in aligning technology and pedagogy in tune with students' interests and learning preferences.

During the Covid-19 lockdown, with a view to reconsidering the idea of pedagogy from traditional chalk-and-talk method to online/blended learning, the Indian Government launched the initiative called "Bharat Padhe Online" to encourage the teachers to create digital educational contents, share ideas and innovations in public platforms by creating educational blogs, wikis and creating more and more OERs. To provide the continuous learning support services to the learners at all levels, various task forces had been formed to 
monitor the online learning environment across the nation - from nation to state and then from state to district levels. But, as observed by Garg (2020), the Covid-19 pandemic had affected higher education like never before. Initially, everyone from political leadership to academic administrators was confused as to what course of action to be taken. After considerable discussions and debates, it was decided that teaching-learning be shifted to emode so as to save human lives as well as to compensate the loss of academic semester. Therefore, the change was abrupt, drastic, posing unique challenges to both teachers and students. Teachers had to undergo digital transformation overnight, overcome technology phobia and work so hard for the sake of their students. When the educational institutions in India switched over to online education overnight, the teachers shifted from blackboard to computer screen, as opined by Meena (2020). But strictly speaking, online education, in its strict sense, was not actually practised.

Against these unprecedented contexts, there is an urgent need to explore the perception of the teachers and learners on the use of online/blended learning particularly in the conventional universities and colleges, the challenges in the implementation of the online/ blended learning and how to mitigate the existing digital division in a country like India. When the different ICT-based practices had already changed the entire teaching-learning pedagogies and have redefined the role of tutoring, mentoring and counselling across the world, the case of online/blended learning in India was not that vibrant. However, the coronavirus pandemic in a way compelled the F2F and ODL institutions to adopt technologies for delivering contents to the learners undisruptively. In fact, by using the affordable, accessible and cost-effective technology, the benefits of education can be uniformly disseminated to all irrespective of any socioeconomic discrimination. There is practically no doubt that teachers in India are now undertaking Facebook Live classes, resorting to Google classroom, uploading contents on YouTube, teaching through WhatsApp and meeting apps like Zoom, Cisco WebEx or Google Meet as an emergent response to the Covid-19 crisis. But whether such efforts are actually transforming the Indian educational system from the pedagogical point of view is a matter of serious discussion. Therefore, it is high time we seriously addressed, which is also the purpose of this paper, the perception of both teachers and learners towards the use of online/blended learning in their regular curriculum transactions during the Covid-19 pandemic so that both teachers and learners in Indian colleges and universities are able to continue their transactions without any disruption and so that a proper roadmap is prepared for the judicial use of online/blended learning at the policy level particularly in post-Covid-19 situations. Otherwise, the slogans of better and sustainable education shall always remain a far cry in a populous country like India.

\section{Objectives of the study}

The basic objectives of the paper are:

(1) To understand the perceptions of the teachers and learners regarding the use of online/blended learning modes.

(2) To find out the prospects and challenges of providing online/blended learning in a country like India.

(3) To propose the measures to be undertaken for providing quality online/blended learning models in post-Covid-19 situations so that an appropriate pedagogy can be adopted in India.

Apart from the three main objectives, there will be some additional research questions that will help to achieve the stated objectives of the study. They are as follows. 


\section{AAOUJ 16,1}

Objectives of the study Research questions

Objective 1

1.1 What is the perception of the teachers regarding the use of online/blended teaching? 1.2 What is the perception of the students/learners regarding the use of online/blended learning?

1.3 Are the teachers and learners aware of ICT-based support practices in teachinglearning processes?

1.4 If yes, which support practice has been most effective during the Covid-19 pandemic?

1.5 Are the teachers and learners aware of the different courses offered by the Commonwealth of Learning (COL), Canada, during the Covid-19 for the capacity building of the school teachers, college teachers and lifelong learners?

Objective 2 2.1 Which digital device was mostly used while accessing academic contents/services, during Covid-19?

2.2 What were the main reasons for considering electronic self-learning material (e-SLM)/e-book as more effective during the lockdown period?

2.3 How did live online classes help the teachers and learners to develop ICT-based knowledge and skills during the lockdown?

2.4 Which social media were the most beneficial during the lockdown and post-lockdown period?

2.5 Does teaching-learning online or in blended form help to assess self-development as a teacher or learner?

2.6 What is the basic hurdle in offering and undertaking courses from SWAYAM and other MOOC platforms?

2.7 What are the main problems in accessing online learning materials?

Objective $3 \quad 3.1$ How conveniently can the teaching-learning transactions be carried out in a post-Covid-19 situation in India?

3.2 What types of teaching-learning transactions should be adopted for mobilising the education system in India without any disruption?

\section{Methodology}

This paper is based on both primary and secondary data. While preparing this paper, an explorative and descriptive research methodology has been used. The academic analytics approach has also been used in the study, as the purpose of the paper was to discuss the perception of the teachers/educators and learners regarding online/blended learning. Academic analytics is an approach that usually guides the researchers to explore academic problems in an empirical way. It also helps to conduct a thorough study of the problems and provide guidance to adopt the strategies to overcome the problems and so on. In the present academic environment, academic analytics can be a very useful approach, as it is found that due to the Covid-19 pandemic, the educational institutions all over the world were closed, and students from all over the world had suffered a lot in accessing education in regular or normal way. Therefore, the academic analytics approach is to be seen as a means of offering some alternative arrangements so that learners can access education without the disruption. In fact, academic analytics would help the educational organisations to identify the prospects and challenges of the current situation in terms of admission, educational transactions and other managerial or administrative functioning in an educational institution.

Therefore, to understand the feasibility of a techno-based teaching learning, and as it has the potential to improve the state of teaching learning and student success, the academic analytics approach has been used during the research. Besides, through the findings of the research, policies or strategies could be adopted for the betterment of the existing education system across India so that education can be accessed by the learners in an affordable way. 
A structured questionnaire was designed by the authors in Google Forms following a consultation with the participants, colleagues and some learners who attended an International Online Conference held by KKHSOU in collaboration with CEMCA on 21-22 April 2020 when the Covid-19 lockdown in India was going on. The questionnaire was mostly designed on the basis of the feedback received from the participants from different parts of India and abroad regarding online/blended learning, and analysis was carried out using Google Analytics. Teachers and learners from both conventional and ODL institutions across different parts of India were selected as the respondents for the current study. However, a majority of them were from the regular mode institutions. Because, the teachers and learners from the ODL mode were more comfortable to use the digital devices compared to those serving in the regular mode. Therefore, as part of the study, more emphasis was given on the perceptions of the teachers and learners from the regular mode regarding the use of online and blended learning. Besides, during the study, more response was received from the teachers than from the learners/students. Further, analysis of the data received had been done by using simple statistical tool like percentage.

As part of the common questionnaire meant for both the teachers and learners, questions seeking the basic information such as - their background, their location, name of the educational institution, mode of the institution, awareness level regarding the use of ICT-based devices for teaching-learning transactions, effective techno-based devices during and post-Covid-19 situation, awareness regarding the online courses provided by international organisation, reasons for considering e-SLMs during Covid-19 lockdown, enhancement of the know-how techniques in using online devices, effectiveness of social media, courses provided by SWAYAM, use of OERs and MOOCs and their actual implementations, the existing hurdles and suggestions for improving the academic transaction to all, etc. were asked.

For the study, initially, the link of the questionnaire was sent to the equal numbers of teachers and students/learners (100 teachers and 100 students) randomly; however, only 79 teachers and 41 students had responded to the questionnaire. Thus, the total sample size for the research was 120 . However, while collecting the samples, random sampling technique was used to select the actual respondents from the states belonging to North Eastern part, Western part, Northern part and Southern part of India as the representative samples. The data collection was done in the first part of the month of May 2020.

\subsection{Secondary source}

Various research studies, reports and data, regulations available in the Web resources of UGC, AISHE 2019, SDGs 2016, etc. were also used as part of the research study.

\section{Analysis and findings}

This research was based on a study of the perceptions of120 teachers and learners, and as already stated above, data were collected from a few librarians of colleges. The following Table 1 and Figure 1 reflect the Indian states from which educational institutions were randomly selected as well as the percentage of the classifications of the respondents.

As shown in Table 1, the educational institutions were selected from the North Eastern, Western, Northern and Southern parts of India so that they would represent the country as a whole. Again, if we see the number of teachers and students and the mode of the educational institutions, it is seen that the majority of the respondents are teachers, and they belong to the conventional mode compared to the ODL mode. In fact, during the Covid-19 crisis, it has been seen that in India, a large number of students from the conventional institutions had been 


\begin{tabular}{lllr}
\cline { 2 - 3 } AAOUJ & Sr. No. & Select states of India & Numbers of the respondents \\
\cline { 2 - 4 } & 1 & North Eastern part of India & 16 \\
& 2 & Bihar & 6 \\
& 3 & West Bengal & 7 \\
$\mathbf{4 8}$ & 4 & Rajasthan & 8 \\
& 5 & Mumbai & 8 \\
& 6 & Gujarat & 8 \\
& 7 & New Delhi & 10 \\
& 8 & Chandigarh & 9 \\
Table 1. & 9 & Maharashtra & 7 \\
Number of respondents & 13 & Tamil Nadu & 6 \\
and selected states & 14 & Puducherry & 8 \\
of India & 11 & Chhattisgarh & 10 \\
\hline
\end{tabular}

Figure 1.

Representatives respondents from the select states of India
Number of the Respondents

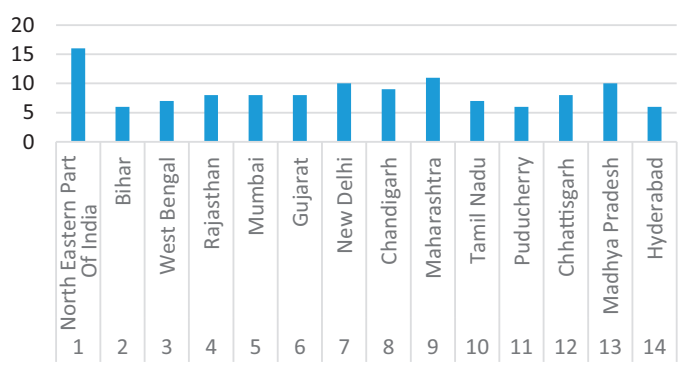

affected, and also, there is a general perception among the teachers and students in the conventional institutions that they are a bit reluctant to use online learning in their normal teaching-learning practices. Therefore, through this study, an attempt was made to understand the perceptions of the teachers and learners on the use of online/blended learning particularly those who belonged to the regular mode educational institutions. The following Figures 2-4 shall provide the basic information of the respondents as well as the nature and mode of their educational institutions.

From Figures 2-4, it has been observed that out of 120 respondents, $55.5 \%$ were from universities, $39.5 \%$ from colleges and about 5\% from institutions other than universities and colleges. Out of them, $66.4 \%$ were teachers, $21 \%$ students and $12.6 \%$ librarians and researchers. Besides, $71.4 \%$ of data were collected from the conventional institutions and $28.6 \%$ were from ODL institutions.

Regarding the support services for delivering and receiving the academic contents, it was found that the majority, i.e. $75.9 \%$ respondents, agreed that a mobile app has been most effective during Covid-19, or it will remain to be effective during any crisis situation, as it is cheaper or affordable and accessible to all followed by digital library, website, learner's portal, LMS, etc. Figure 5 provides an idea of the perception of the respondents regarding various digital support services.

Thus, from Figure 5, it is found that the mobile app could be the strongest support service that could meet the learning requirements of the learners during any crisis moment, flood or 


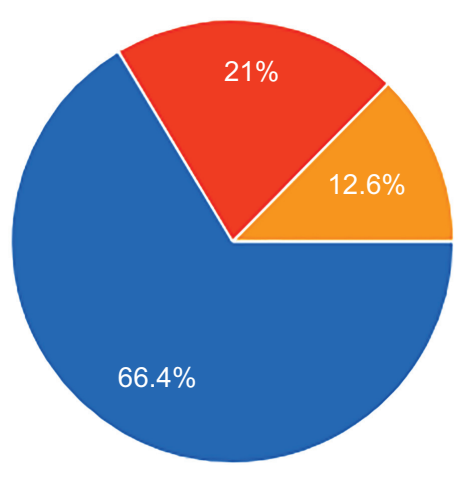

\section{Online/blended learning during \\ Covid-19}

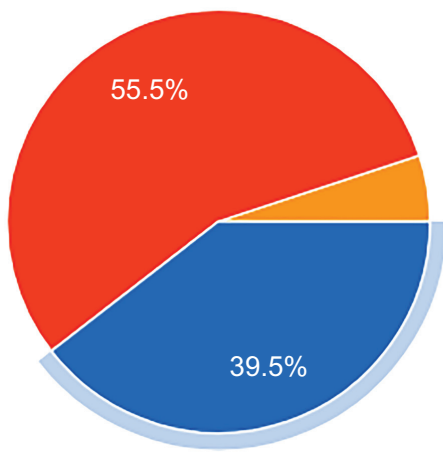

College
University
Others

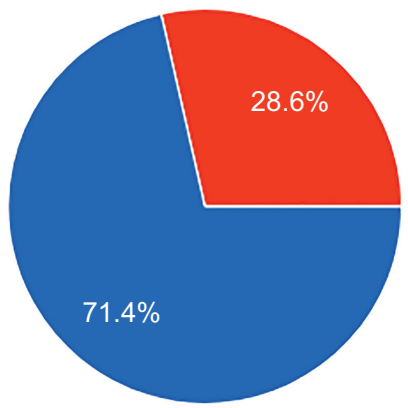

Conventional

ODL

Figure 4.

Mode of institutions

any natural disaster. From Figure 5, it is also seen that the Indian Government has taken many initiatives for popularising online learning in India through SWAYAM, but the percentage is very low in case of SWAYAM as well as other social networking sites like Facebook, WhatsApp, YouTube, etc. as means of online education.

During the study, it was also explored that during Covid-19, $84.9 \%$ respondents used smartphones, followed by $73.1 \%$ laptop, $16.8 \%$ personal computer and $2.5 \%$ iPad for receiving and delivering e-contents. The following Figure 6 shows the percentage of device use during the Covid-19. 


\section{AAOUJ 16,1}

Figure 5.

Perception of the respondents on various support services

Figure 6.

Most effective digital device during Covid-19
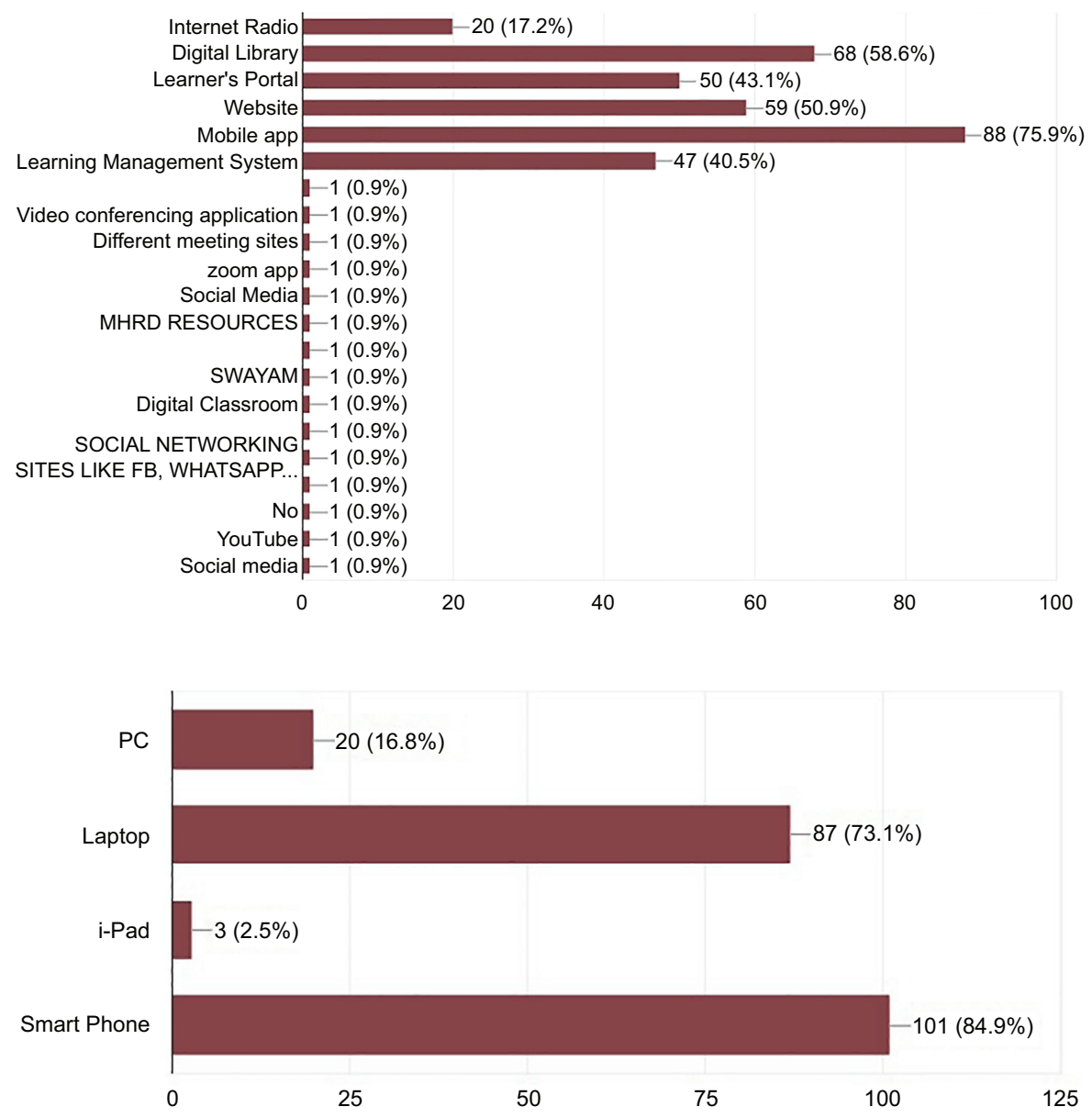

Regarding the perception on the effectiveness of printed self-learning materials (SLMs)/ textbooks or e-SLMs/e-books during Covid-19, it was found that the majority of the respondents preferred e-SLMs/e-textbooks to printed SLMs and textbooks. The following Figure 7 shows the percentage of preference.

One important finding of the research is that out of 120 respondents, only 17 preferred printed SLMs, and out of them 11 were teachers and six students. Besides, out of the 17 respondents, 12 respondents were from the conventional institutions and five from ODL institutions. However, the most important finding was that there is a general perception that people from the rural areas are not capable of using the internet or e-resources, but from the study, it has been found that out of 17 respondents, 14 were from urban areas, and they preferred to use printed materials even during the pandemic situation.

Apart from the percentage of using e-SLMs, as Figure 8 reveals, e-SLMs are easily accessible anytime and anywhere, as stated by $82.3 \%$ respondents. While $40.7 \%$ respondents opined that online version solves the problems of not getting the SLMs or textbooks on time, $34.5 \%$ respondents stated that e-contents are more user-friendly, and $25.7 \%$ opined that e-contents provided ease of reading particularly during the Covid-19 lockdown period. 
It was also seen that online/blended learning has the capability to offer both the teachers and learners independence, as well as opportunities to develop their own technology skills and update their knowledge on the proper use of ICT-based technologies for delivering and receiving the academic contents.

For the sudden nation-wide lockdown that had started since the last part of March 2020 due to the Covid-19 pandemic, it has been observed that the teachers started using many technological tools for conducting classes for the learners who also accessed the contents online to cope with the changing situation in the academic environment. From the study, it Online/blended learning during Covid-19 has been found that more than $50 \%$ respondents agreed that accessing live online classes helped them (both teachers and learners) to develop ICT-based knowledge and skills during the lockdown. A few respondents (less than 3\%) disagreed that the preparation or accessing live classes could help them to develop their skills on the use of ICT-based technologies during the lockdown period (Figure 9).

Besides, when the respondents were asked about the most effective synchronous and asynchronous tools for transacting the learning contents during the lockdown period, $47 \%$ revealed that meeting applications like Zoom and others are the most effective tools followed by emails and WhatsApp (20.5\%), Google Classroom (12.8\%) and a very few percentages agreed about the effectiveness of YouTube, Facebook Live class, LMS and Skype, etc. The following Figure 10 shows the percentage of the use of technological tools.

Regarding the awareness level on ideas of OERs and MOOCs, it was seen more than $90 \%$ teachers and learners across the nation heard the terms irrespective of the mode of their educational institutions and locations, but there were some basic differences on the perceptions of the teachers, as $57 \%$ agreed that OERs is most beneficial for disseminating knowledge to the learners during the pandemic or any crisis situation and $43 \%$ agreed upon MOOCs, as can be seen in Figures 11 and 12.

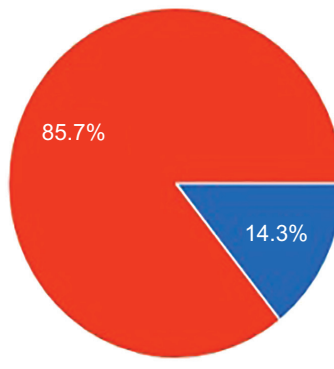

Figure 7.

Effectiveness of printed SLMs/ textbooks or e-SLMs/ebooks during Covid-19

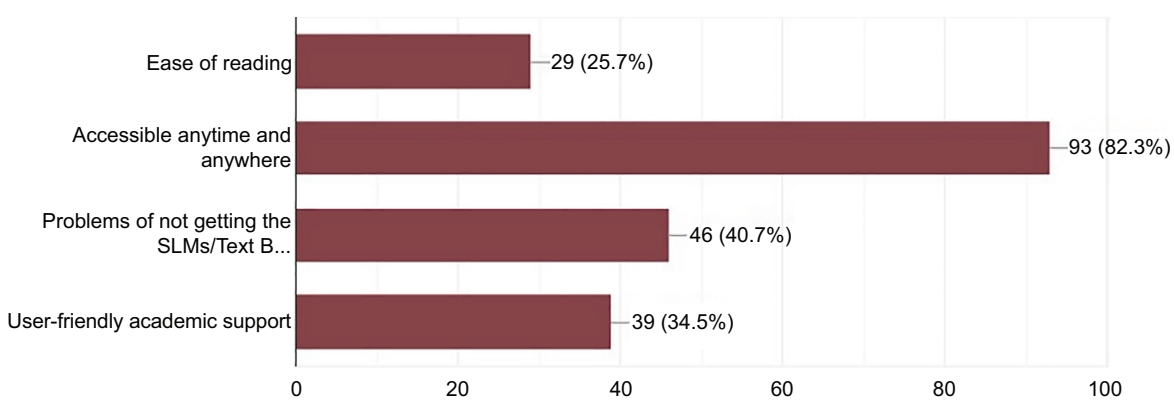

Figure 8.

Reasons for effectiveness of e-SLM/ e-book during the lockdown period 
AAOUJ Regarding the enrolment in any MOOC, $52.1 \%$ respondents did not enrol in any courses 16,1 offered by a MOOC platform. However, there is a mandate of the Indian Government that at least $20 \%$ courses should be offered or adopted through the SWAYAM. Also, 47.9\% respondents enrolled and received courses through the MOOC platform, but the interesting point is that out of this percentage, the teachers and librarians from conventional universities and colleges took refreshers courses through SWAYAM. However, only two students were found to enrol in postgraduate programmes under UGC in the SWAYAM platform (Figure 13).

Besides from the study, regarding the basic hurdle in adopting and undertaking the courses from SWAYAM and other MOOC platforms, 38.9\% respondents revealed that the course contents are not at par with their syllabi, $32.6 \%$ revealed that it is difficult for credit transfer, $25.3 \%$ stated it to be difficult to enrol and, lastly, $21.1 \%$ said that the courses offered

Figure 9.

Perception on accessing live online classes

\section{Figure 10.}

Most effective tool for content transaction during the lockdown

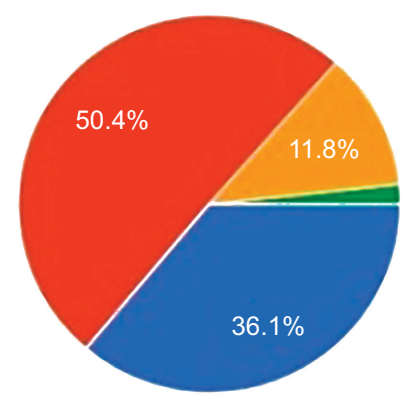

Strongly Agree

Agree

Can't Say

Disagree

Strongly Disagree

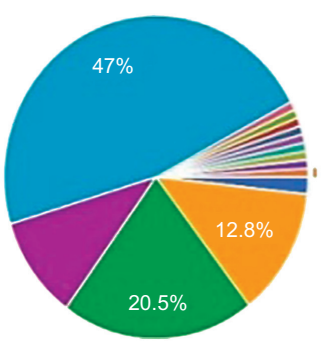

Facebook live class

Blogs \& Twitters

Google Classroom

Emails, WhatsApp

YouTube

Meeting Application like ZOOM and ot..

SKYPE

Lms

$1 / 2 \nabla$

Figure 11.

$\%$ of respondents knowing OERs and MOOCs

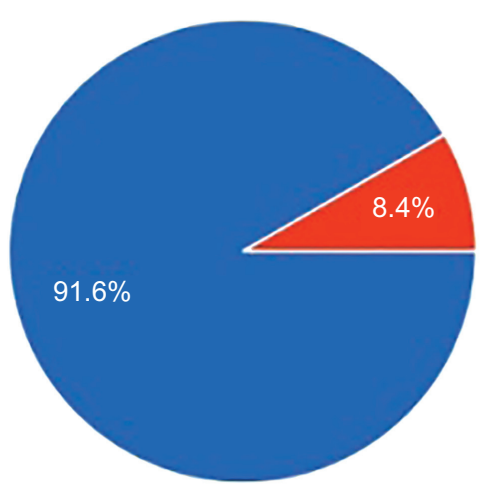




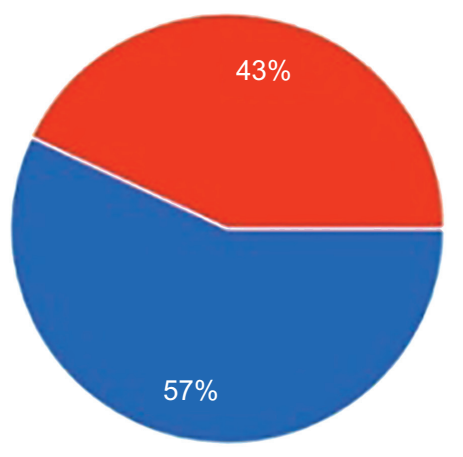

\section{Online/blended learning during Covid-19}

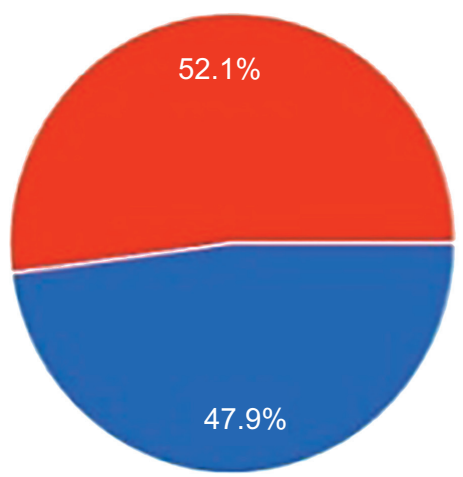

Figure 13. Percentage of enrolment in MOOCs in India

in the MOOC platform are not learner-centric. The following Figure 14 shows the perception of the respondents regarding MOOCs.

Apart from the finding on the basic hurdles in adopting or taking courses from SWAYAM and other MOOC platforms, from this study, it was also observed that the majority of the respondents $(81.4 \%)$ knew about the pedagogical issues related to the four quadrants

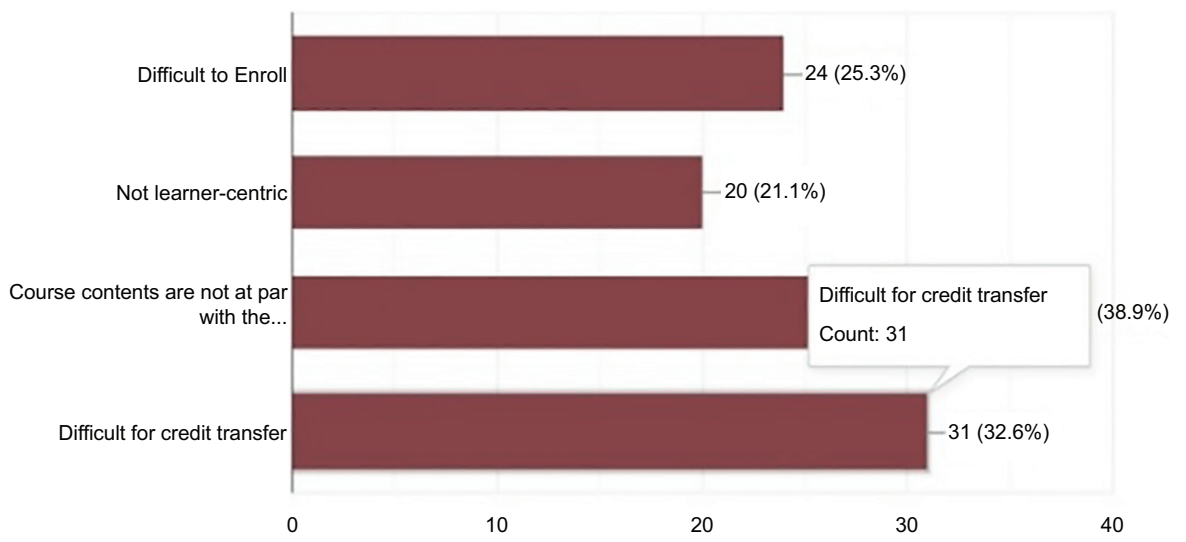

Figure 14.

Basic hurdle in adopting and offering MOOCs in SWAYAM or in other platforms 


\section{AAOUJ} 16,1

\section{4}

Figure 15.

Perception on "Four quadrants" of online programme. However, most of the respondents revealed that videos and e-materials are most useful for content delivery, as shown in Figure 15. The following Figures 15 and 16 show the perception of the respondents regarding the four quadrants of online learning.

To know the perceptions of the respondents in carrying out teaching learning transactions in future as well as in the post-Covid-19 situation, from the study, it is found that $62.2 \%$ respondents preferred the blended form of learning, followed by $22.7 \%$ online and $15.1 \%$ off line learning. From the study, it also observed that most of the respondents from the conventional mode preferred blended learning. Figure 17 provides an idea of the preference to blended learning.

Regarding the awareness level of the respondents on different courses offered by the COL, Canada, during Covid-19 for the capacity building of the school teachers, college teachers and lifelong learners, it was seen that $53.8 \%$ respondents were aware of the courses and the majority of the respondents were from open universities and ODL institutions than the conventional ones. Figure 18 shows the awareness level of the respondents on the programmes offered by the COL during Covid-19. Besides, the teachers were better informed than the learners in the ODL mode institutions compared to the teachers in the conventional mode about such courses.

As per the 2019 record available in www.statista.com, India is the second largest online market in the world, after China with over 560 million internet users. It has been predicted that by 2023 , there would be over 650 million internet users across the country. However, against the large base of internet users in India, theinternet penetration rate in the country stands at around $50 \%$ in 2020 . This means that around half of the 1.37 billion Indians would have access to internet this year.
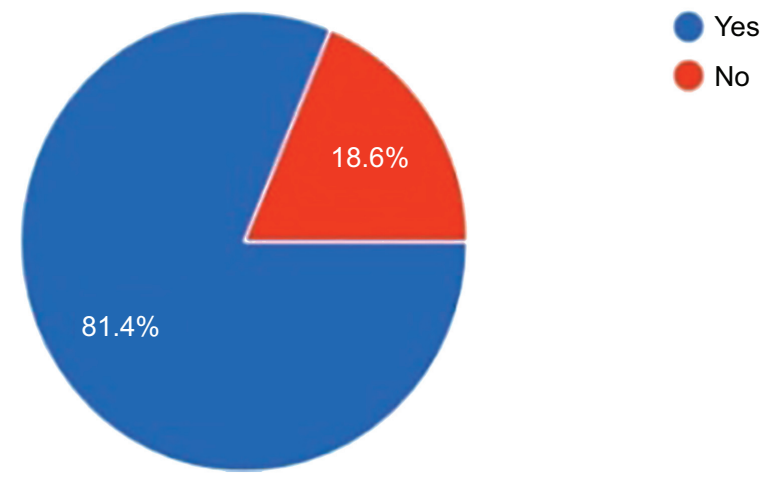

Figure 16.

Knowledge on "four quadrants"

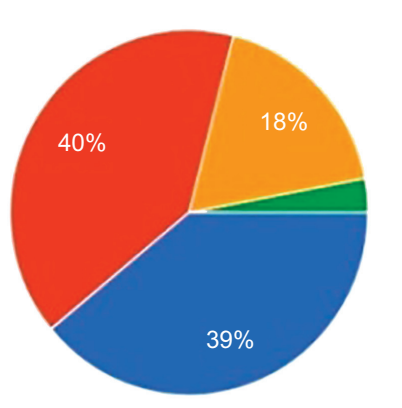

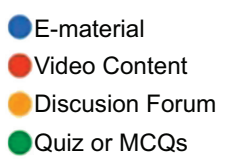


The following Figure 19 refers to the major hindrance or challenge in accessing online materials in India. However, from the study, it was also seen that out of the total respondents, $77.6 \%$ agreed that poor internet connectivity in their locality is the main problem in availing online learning facilities. Apart from the internet connectivity, it was also observed that lack of ICT skills (38.8\%), lack of proper digital services $(33.6 \%)$ and poor electricity in the localities $(16.4 \%)$ are some of the other major problems in accessing online resources. Besides, from the study, it was found that internet connectivity and electricity facilities were comparatively lower in the village areas than in the urban areas, which is sure to create a Online/blended learning during Covid-19 digital division among the people of the country.

Thus, from the analysis of the data received from the respondents, it has been found that in India online/blended learning had received new impetus during the Covid-19 pandemic.

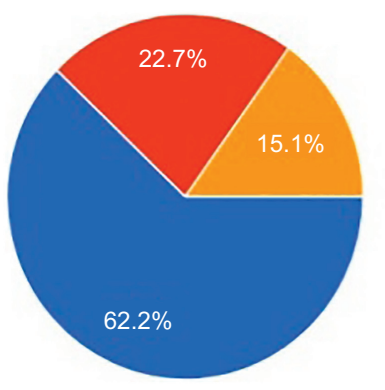

Blended learning

Online learning

Off line learning

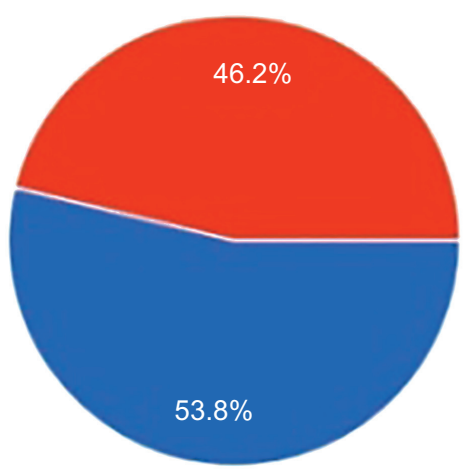

Figure 17.

Best way for teaching learning transaction in post-Covid-19 situations

Figure 18. Awareness on courses offered by COL during Covid-19 pandemic

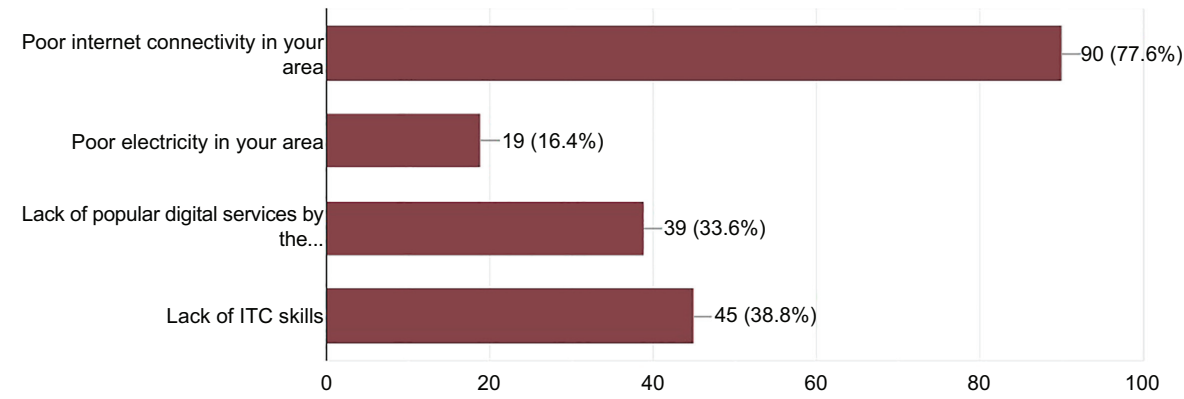

Figure 19. Main problems in accessing online materials 
AAOUJ 16,1

But, accessibility and equity in providing quality learning with the help of ICT-based technologies is still a big challenge for a country like India. Though flexibility in time and place had been considered the most dominant feature of online learning, poor network connection had been one of the biggest hurdles, as Hasan (2020) had also found. Therefore, necessary technical changes must be made in designing online learning that particularly facilitates meaningful peer interaction. The motto of "Bharat Padhe Online" could be met practically only when the teachers and learners are able to understand the proper implementations of the latest techno-pedagogies that could transform the education system. As both Hasan (2020) and Garg (2020) mentioned, instead of starting online teachinglearning in an unplanned and hurried way, understanding students' practicalities and their priorities in learning online, their learning preferences and challenges had to be outlined beforehand. When the educational institutions in India switched over to online education overnight, the teachers shifted from black board to computer screen. But truly speaking, online education in its strict sense was rarely practised.

Besides, it has been found that online/blended learning requires systematic planning, designing and careful formulations of the aims and objectives of education so as to create an effective learning ecosystem. Though during the pandemic, teachers are often engaged in a variety of online activities, in essence, this is rather a temporary solution and "not" online learning per se, which should involve all the "four quadrants" of online learning. As opined by Bozkurt and Sharma (2020), such a distinction will play a significant role in the development and prosperity of online education in the post-Covid world. In this regard, while considering online/blended education, one should go beyond just uploading educational contents and instead focus on the changing needs of the learners, the changing contexts of their learning and the availability and accessibility of feasible technological tools to facilitate such learning, which also means that one has to use different strategies and approaches to address the individual cases with different priorities.

From the study, it was also found that the teachers should rather play the role of facilitators, and there is a need of providing training to the teachers on the use of the latest technologies to ensure the effectiveness of the existing systems of teaching learning. Besides, the social presence, teaching presence and cognitive presence, which are the three pillars of quality online/blended model, should be reflected in the contents provided having strong linkage between in persons and online tools. In fact, the use of online/blended techniques in the teaching learning process is becoming more and more significant day-by-day, and the pandemic has been a blessing in disguise in asserting a transformed role of online/blended learning for all types of education in a country like India. Time will, however, say how e-teaching using technological tools such as Google-group, Zoom meeting platform, LMS, etc. will be universalised in the country with the implementation of the National Education Policy (NEP) 2020 by the GOI.

\section{Suggestions and recommendations}

The following are some areas in which the higher educational institutions in India can take leadership in transforming the educational scenario of India based on the experiences gained during the Covid-19 pandemic.

\subsection{Reconsideration of teaching learning pedagogies}

During and after the pandemic-led lockdown in India, there is a need to reconsider the very idea of pedagogy as a technique, an approach, a process and a method that would help to make teaching learning effective in the real sense. A thoughtfully formulated technopedagogy at this critical stage could guide the teachers in using the appropriate teaching 
tools and techniques to fulfil the mission and objectives of education. Therefore, the pedagogical issues at any given time, like in case of the pandemic, should be aligned with the expected learning outcome. Moreover, in India, the fundamental question related to higher education is how to maintain and ensure access, equity, quality and expansion while imparting education so that democratization of education can be ensured in the true sense. The convergence approach between the conventional and ODL institutions should be promoted for a better collaborative experience so that the learners from both the modes can reap the benefits of learning at their own place and pace.

\subsection{Capacity building of the teachers/educators regarding the use of online/blended learning for content delivery}

It is seen that during the pandemic, teachers in higher education are already utilising facilities like Facebook Live classes, Google classroom, Skype tutorial, audio-visual classes through WhatsApp, personal blogs and meeting apps like Zoom, Google Meet, etc., which have given much respite to the learners. But, while providing online education, the "four quadrants" of learning, namely, e-materials, video contents, discussion forum and quiz or multiple-choice questions (MCQs) are not to be compromised. So, the capacity building of the teachers or content developers/providers must be done on a priority basis so that they become familiar with the fundamental concepts of online learning, besides getting rid of the technology phobia. There is an urgent need to organise a series of training activities for the teachers/educators/ counsellors of both the conventional and ODL institutions by tying up with different national and international agencies like CEMCA, New Delhi; COL, Canada, UNESCO, Paris etc., which have been regularly conducting different training programmes in that line for sensitising and building the capacity of the teachers across the whole world. In such programmes, the teachers can also be provided need-based training on offering and adopting online MOOCs through SWAYAM, GOI or on creating audio-visual contents on locally relevant areas for the SWAYAMPRABHA channel in both English and local regional languages.

\subsection{Uniformity in the course contents}

As found during the research, syllabi not being at par with the course contents has been one of the major hurdles for which the learners are not motivated to enrol in MOOCs provided by SWAYAM. In this context, uniformity of the curriculum across the whole nation is the need of the hour so that the same educational contents can be accessed by all in an equitable manner. For example, for a professional teachers' training programme like Bachelor of Education (BEd), there is a standard national curriculum designed by the National Curriculum Framework, which needs to be followed by all institutions across India offering (BEd). However, for general courses, though there are some model curriculums as well as guidelines provided by the UGC, in terms of its actual implementations, there can be seen much inconsistency which nullifies the possibility of a uniform curriculum across the nation. Therefore, the Indian policy makers must try to implement a uniform curriculum, which will greatly reduce the problems of inclusion and access in the field of higher education. It would certainly help the Indian learners in credit transfer across different Indian educational institutions.

\subsection{Creating an open educational resources repository}

In the 21st century, OERs in online/blended learning have significantly altered the ways of teaching-learning transactions. So, a new type of social constructivism has evolved to help a learner directly interact with the people in the community, share their ideas and thoughts among their peers as well as their teachers and collectively undertake the new researches, which could genuinely transform the society. This kind of constructivism may prove to be 
AAOUJ 16,1

very useful in the pandemic situation. In this context, the GOI may take an initiative to create a National OERs Repository in collaboration with the UNESCO (as UNESCO has already developed an OER repository)so that institutional learners, teachers and other lifelong learners from anywhere across the nation and beyond can continue to learn without any disruption even during a crisis situation. Here, the recent initiative of the Indian government to form a "National Academic Repository of Open Courses" may turn out to be a milestone for meeting the aspirations of the different stakeholders during the "new normal" in the country.

\subsection{Adoption of learning management system (LMS)}

The latest developments in the adoption of choice-based credit system (CBCS) starting from school education to higher is going to transform the entire education systems across India. This will also provide opportunity to the learners from different parts of the country to reap the benefits of a global form of learning. Even in the pandemic situation, the LMS can be the most effective way to offer education at the door step of every learner located in different corners of the country. In fact, through the use of LMS, both the conventional and ODL institutions can share their educational contents among their own learners. This can be a major change that might transform the field of education of the whole country and provide collaborative learning opportunities to the intended learners in the real sense. Therefore, it is the right time to formulate a national policy to introduce an LMS-based learning from school education to higher or to create own institutional LMS to reach out to the learners.

\subsection{Adopting suitable policies for collaborating with community communication centres and community information centres at the blocks of the districts}

Accessing the students in the rural areas has been a major problem in all states of India. Besides, the low level of internet connectivity and poor electricity are some additional hurdles. Hence, the central government may take important initiatives at the policy level to mitigate these issues so that education can actually reach the needy beyond all barriers. During the pandemic, the universities and colleges may collaborate with the community communication centres (CCCs) and community information centres (CICs) located in different blocks of the districts in providing the required information to the desiring learners, and all the state governments of India can also come up with a policy to assist the universities and colleges in formulating the road map for such collaborations.

\subsection{Blended learning models as the alternative in post-Covid-19 situation in India}

From the study, it has been found that majority of the respondents preferred the blended form of learning as the most suitable model of learning in the coming days in the Indian context. India being a large economy, there are some variations in terms of accessing modern sophisticated tools for educational transactions by the teachers and learners alike. Besides, it has also been found that due to the low level of internet connectivity for educational purposes, it is not possible to access fully online or synchronous teaching learning facilities by all in equitable way. Therefore, the asynchronous ways in education can provide the optimum learning opportunity to all in a more flexible and convenient way. So, the blended form of learning, which is generally learner-centric and cost-effective, is going to influence the entire Indian educational scenario in the days to come.

\section{Conclusion}

In a country like India, with specific challenges to meet at the current situations, the "one-sizefits-all" concept may not work. Therefore, before putting certain online/blended activities into practice, one must take into consideration the many variables, including the target learners, 
their social, cultural and economic backgrounds, their age range, their access to technological infrastructure, the technology readiness on the part of the educational institutions and so on. The developed countries may be having the advantage to initiate emergency online and remote teaching during a crisis phase. But, the same may not be applicable to all countries of the world. For example, in India, problems like digital divide between the rich and the poor, the haves and have-nots are to be seriously addressed because the poorest and the most vulnerable sections of learners are the hardest hit both by the pandemic and by the kind of response emanating from the educational institutions. Sadly, therefore, while many countries Online/blended learning during Covid-19 have been suffering from the disruptions in education, in a country like India, the digital divide can still be perceived as one of the greatest threats to the implementation of successful online/blended mode, as many still suffer from scarce educational opportunities. Besides, the systematic integration of technology in teaching and learning in higher education institutions through policy implementation, capacity building and the use of appropriate low-cost technologies can actually become the harbinger of change. Therefore, this study had been undertaken to know the perceptions of the teachers and learners on online/blended learning so that a suitable roadmap could be prepared at the policy level, and a quality online/blended learning design could be developed to help both the teachers and learners to happily cope with any crisis situation at present as well as in future.

\section{References}

Baytiyeh, H. (2018), "Online learning during post-earthquake school closures”, Disaster Prevention and Management, Vol. 27 No. 2, pp. 215-227, available at: https://www.emerald.com/insight/content/ doi/10.1108/DPM-07-2017-0173/full/html (accessed 27 May 2020).

Bordoloi, R. (2018), "Transforming and empowering higher education through open and distance learning in India”, Asian Association of Open Universities Journal, Vol. 13 No. 1, pp. 24-36, available at: https://www.emerald.com/insight/content/doi/10.1108/AAOUJ-11-2017-0037/full/ pdf?title=transforming-and-empowering-higher-education-through-open-and-distance-learningin-india (accessed 25 September 2020).

Bozkurt, A. and Sharma, R.C. (2020), "Emergency remote teaching in a time of global crisis due to Corona virus pandemic", Asian Journal of Distance Education, Vol. 15 No. 1, pp. i-iv, available at: https://www.researchgate.net/publication/341043562_Emergency_remote_teaching_in_a_ time_of_global_crisis_due_to_CoronaVirus_pandemic (accessed 27 May 2020).

Daniel, J. (2020), Education and the Covid 19 Pandemic, available at: https://ink.springer.com/content/ pdf/10.1007/s11125-020-09464-3.pdf (accessed 26 May 2020).

Davies, L.J., Chiocca, E.S., Hiller, K.E., Campbell, M. and Naghib, S.L. (2020), “Transformative learning in times of global crisis: reflections on collaborative working practices", CEA Critic, Vol. 82 No. 3, pp. 218-226, doi: 10.1353/cea.2020.0036 (accessed 27 January 2021).

Garg, S. (2020), Artificial Intelligence and its Impact on Higher Education in Post COVID Era, University News, Association of Indian Universities, New Delhi, Vol. 58 No. 36, pp. 2-6.

Harrad, R. and Banks, N. (2016), "Counselling in online environments", in Attrill, A. and Fullwood, C. (Eds), Applied Cyberpsychology, Palgrave Macmillan, London, doi: 10.1057/9781137517036_8 (accessed 23 January 2021).

Hasan, N. (2020), "Online teaching-learning during covid-19 pandemic: students' perspective", The Online Journal of Distance Education and e-Learning, Vol. 8 No. 4, pp. 202-2013, available at: https://www.researchgate.net/publication/344932812_ONLINE_TEACHING-LEARNING_ DURING_COVID-19_PANDEMIC_STUDENTS\%27_PERSPECTIVE (accessed 23 January 2021).

Hass, A. and Joseph, M. (2018), "Investigating different options in course delivery-traditional vs online: is there another option?", The International Journal of Information and Learning Technology, Vol. 35 No. 4, pp. 230-239, available at: https://www.emerald.com/insight/content/ doi/10.1108/IJILT-09-2017-0096/full/html (accessed 27 May 2020). 
AAOUJ 16,1
Mckay, C., Fowler, C., Freitas, J., Heumann, M., Knudson, K. and Smith, P. (2018), Ensuring Effective Online Education Programs: A Faculty Perspective, available at: https://asccc.org/sites/default/ files/OEPaperFinal3.12.18.pdf (accessed 25 January 2020).

Meena, M.K. (2020), "Living the teaching life in a time of COVID-19", CEA Critic, Vol. 82 No. 3, pp. 266-270, doi: 10.1353/cea.2020.0020 (accessed 27 January 2021).

MHRD, Department of Higher Education, Govt. of India (2019), “All India survey on higher education 2018-2019”, New Delhi, available at: http://aishe.nic.in/aishe/viewDocument.action? documentId=262 (accessed 1 September 2020).

MHRD, Govt. of India (2016), "UGC (Credit framework for online learning courses through SWAYAM) regulation 2016”, available at: https://www.ugc.ac.in/pdfnews/4064990_UGC-(CreditFrameworkfor- Online-Learning-Courses-through-SWAYAM)-Regulation,-2016.pdf (accessed 10 July 2019).

MHRD, Govt. of India (2020), "National education policy", available at: https:/www.education.gov.in/ sites/upload_files/mhrd/files/NEP_Final_English_0.pdf (accessed 25 January 2021).

Peake, J. and Reynolds, A. (2020), "Implementing social media bridges for student-teacher chasms created during the COVID-19 pandemic”, CEA Critic, Vol. 82 No. 3, pp. 274-284, doi: 10.1353/cea. 2020.0022 (accessed 27 January 2021).

United Nations, New York (2016), The Sustainable Development Goals Report, New York.

University Grants Commission (2020), "UGC (open and distance learning programmes and online programmes) Regulations, 2020”, available at: https:/www.ugc.ac.in/pdfnews/221580.pdf (accessed 6 September 2020).

\section{Corresponding author}

Ritimoni Bordoloi can be contacted at: ritimonibordoloi@gmail.com

For instructions on how to order reprints of this article, please visit our website:

www.emeraldgrouppublishing.com/licensing/reprints.htm

Or contact us for further details: permissions@emeraldinsight.com 